\title{
Practice Spotlight: Pharmacist Practice in Rural Saskatchewan
}

\author{
Karen McDermaid, BSc, BSP, ACPR, CDE \\ Manager, Rural Pharmacy Services \\ Regina Qu'Appelle Health Region \\ Moosomin, Saskatchewan
}

$T$ he Regina Qu'Appelle Health Region (RQHR) is the largest health care delivery organization in southern Saskatchewan, covering a diverse geographic area of about $26663 \mathrm{~km}^{2}$. It provides tertiary care in 2 provincial hospitals, both located in Regina, and offers a full range of hospital, rehabilitation, community and public health, long-term care, and home care services to meet the needs of more than 260000 residents living in cities, towns, villages, rural municipalities, and First Nation communities within the Region. The Pharmacy Department is structured as a regional service.

Pharmacy services for 5 community hospitals and 6 community health centres within the RQHR are supported by the Pharmacy Department, which is based in Moosomin, a town located just over $200 \mathrm{~km}$ east of Regina, near the Manitoba border. When Karen McDermaid moved to Moosomin in the early 1990s, after completing a hospital residency in Regina, she was uncertain what pharmacy practice in rural Saskatchewan would hold. She has since discovered that hospital pharmacy practice in this part of the country offers endless opportunities, allowing practitioners to fully develop their potential, to become all they can be.

Soon after starting in Moosomin, Ms McDermaid was asked by the local nurse and dietitian if she would like to become involved in diabetes education. Thinking that this would be a good area of practice for pharmacist involvement, she jumped in with both feet, unaware of the opportunities that would follow. There is growing evidence to support the addition of pharmacists to diabetes management teams, including improvements in hemoglobin A1c and other physiologic measures. ${ }^{1}$ Ms McDermaid now accepts referrals from health care providers or self-referrals from patients wanting assistance with diabetes self-management, and she regularly works with patients who have type 1 , type 2 , or gestational diabetes. The majority of patients are seen in a clinic room in the hospital, and, when possible, the patient's care is shared with a nurse and a dietitian, who visit the community regularly.

To support her role in diabetes education, Ms McDermaid became a Certified Diabetes Educator in 2002. Maintaining her certification has supported her role as a diabetes specialist and has opened many doors for her in the world of diabetes. In 2007, she was asked to become a member of the Canadian Diabetes Association (CDA) Advisory Committee to Identify Promising or Best Practices in Diabetes Education. With the publication of the CDA's 2008 Clinical Practice Guidelines, ${ }^{2} \mathrm{a}$ dissemination and implementation steering committee was formed and Ms McDermaid became involved, chairing the pharmacist subcommittee, to ensure that the voice of the pharmacist was heard, in terms of pharmacists' role in diabetes education. Similarly, when the Canadian Pharmacists Association formed its Advisory Committee for the Diabetes Strategy for Pharmacists, Ms McDermaid became a member. These committee activities reflect what Ms McDermaid sees as her role as an advocate for the profession of pharmacy within diabetes care.

The next steps in Ms McDermaid's diabetes practice will include improving the team approach to care, developing a collaborative practice agreement for the care of patients living with diabetes, and tracking outcome measures for patients under her care.

Another area of interest for Ms McDermaid is cardiac care. In 1995, on a dare from one of the physicians with whom she worked, she became certified in Advanced Cardiac Life Support (ACLS). Then, in 2001, she became an ACLS instructor and has been assisting with courses ever since. Being an ACLS instructor has enhanced her supporting role with the community hospitals within RQHR. Many of the courses with which she assists are presented in rural areas of the RQHR, so she is able to connect in person with nurses and physicians practising at these sites. Also, when available in Moosomin, she serves as a member of the resuscitation team. The presence of a pharmacist on the resuscitation team is associated with improved compliance with treatment guidelines. ${ }^{3}$ This integral role as both instructor and resuscitation team member allows 
Ms McDermaid to keep care teams in the Region's community hospitals current with any changes to ACLS medication recommendations.

Diabetes and cardiac care are small components of Ms McDermaid's day-to-day role in pharmacy within the RQHR. She is also involved with program development, ensuring that medication management standards are met, as well as developing a plan to ensure that patients in community hospitals in rural parts of the RQHR receive care that meets regional pharmacy care standards. Her role as pharmacy manager has given her a better appreciation of the need for pharmacy services to cross care continuums within the health region and the importance of pharmacy as a partner with all patient care professions. There are never enough hours in the day to ensure that the value of the pharmacist is fully understood by all stakeholders in the health care system, but Ms McDermaid takes advantage of any and every opportunity that comes her way.

References

1. Pepper MJ, Mallory N, Coker TN, Chaki A, Sando KR. Pharmacists' impact on improving outcomes in patients with type 2 diabetes mellitus. Diabetes Educ 2012;38(3):409-416.

2. Canadian Diabetes Association 2008 clinical practice guidelines for the prevention and management of diabetes in Canada. Can J Diabetes 2008; 32(Suppl 1).

3. Draper HM, Eppert JA. Association of pharmacist presence on compliance with advanced cardiac life support guidelines during in-hospital cardiac arrest. Ann Pharmacother 2008;42(4):469-474.

\section{几 Canadian Society of Hospital Pharmacists Société canadienne des pharmaciens d'hôpitaux}

\section{Membership Year 2012/2013 (July 1, 2012 - June 30, 2013)}

Are you a current member of the Canadian Society of Hospital Pharmacists?

CSHP has celebrated 65 years of inspiration and leadership among a rapidly growing network of over 3000 pharmacy colleagues. As a member of CSHP, you will have access to resources and opportunities that will enhance your career and help impact the direction of healthcare in Canada. Your participation in CSHP 2015, an initiative challenging all pharmacists to improve patient medication outcomes and safety through advancing pharmacy practice excellence by the year 2015 , is a prime example.

For more information about CSHP, please visit us at www.cshp.ca. We invite you to reap the benefits of an affordable membership with CSHP.

Membership Enquiries: Please contact Membership Services

Bus.: (613) 736-9733 Ext. 222 Fax: (613) 736-5660 Email: membershipservices@cshp.ca 